\title{
ASSESSMENT OF WINTER WHEAT VARIETIES BY THEIR ASSOCIATIVE NITROGEN FIXATION ABILITY
}

\author{
Nadkernychna O. V. ${ }^{1}$, Minenok S. M. ${ }^{1}$, Boguslavsky R. L. ${ }^{2}$, Leonov O. Yu ${ }^{2}$. \\ ${ }^{1}$ Institute of Agricultural Microbiology and Agricultural Production NAAS \\ 97, Shevchenko Str., Chernihiv, 14027, Ukraine \\ ${ }^{2}$ National Centre for Plant Genetic Resources of Ukraine \\ 142, Moskovskyy prospekt, Kharkiv
}

The paper depicts the results of intervarietal variability study of winter wheat plants in controlled environment with varieties Albatross Odessa, Kiriya, Zolotokolosa, Lybid and Odeska 267 by their associative nitrogen fixation ability. The 5.6-13.7-fold divergence between the varieties by given index was revealed.

It was shown that intravarietal variability of winter wheat plants by their ability to stimulate associative nitrogen fixation occurs along with the intervarietal one. Populations intensity of a different genotypes characterized by high nitrogen fixation activity in root zone, stipulates high nitrogen fixation potential of variety.

Among the studied varieties Zolotokolosa was selected as genetically homogeneous variety with high nitrogen fixation potential of rhizosphere microorganisms that can be recommended for use in breeding as a source with high capacity for associative nitrogen fixation. New winter wheat varieties with high nitrogen fixation potential can fully develop using not only mineral nitrogen fertilizers, but also interacting with associative nitrogen fixation microorganisms should partially replace mineral nitrogen with biological that, in turn, will guarantee a high yield quality and conservation of agricultural landscapes.

Keywords: winter wheat, associative nitrogen fixation, potential nitrogenase activity, intervarietal and intravarietal variability by nitrogen fixation potential.

Wheat is one of the most important food crops in the world. It holds a leading position among other cereals and is the most valuable and most widespread crop. Winter wheat has the biggest sowing areas in Ukraine and is the main food crop in the country [1].

Winter wheat is very fastidious to the availability of mineral nutrients in the soil and its water-physical properties [2]. It requires sufficient nutrients supply with optimal ratio of all minerals throughout the growing season [3]. Introduction of high-yield cultivars and especially wheat varieties with high-protein contents into the agriculture practices requires creation in the root zone of plants high concentrations of easily accessible nitrogen.

Therefore, the use of mineral fertilizers is the necessary condition for winter wheat cultivation and increase of its yield. However, introduction of high doses of fertilizers, especially nitrogen, has a negative impact on the environment, since its accumulation leads to soil degradation, eutrophication of reservoirs, etc.

Nitrogen fixation microorganisms present in soil are the alternative to the application of mineral nitrogen $[4-6]$. They renew nitrogen fund in soil that in turn 
significantly affects soil fertility and plants provision with environmentally friendly element [7].

Activity of nitrogen fixation by microorganisms is recommended to determine with acetylene reduction method, which is characterized by high sensitivity, speed and simplicity [8]. M.M. Umarov [9] and V.V. Volkogon [10] have modified this method allowing determining the potential association nitrogen fixation activity of rhizospheric soil and washed plant roots.

The activity of associative nitrogen fixation in the root zone is affected by many factors, among which plant genotype is of a big importance [11]. Early studies of associative nitrogen fixation have revealed that nitrogenase activity in rhizosphere varies depending on the type of soil, if plant and hydrothermal conditions remain stable. In-depth study of varietal diversity of crops by their capacity for associative nitrogen fixation had revealed that, performance of individual varieties may differ depending on the soil conditions, so assessment of specific plant genotypes should be performed subject to environmental conditions [12]. Study of nitrogenase activity in the root zone of plants timothy grass, cock'sfoot grass, awnless brome grass on podzolized chornozem and ashen gray soils had revealed that associative nitrogen fixation is highly dependent on the genotype of the plant rather than on the soil characteristics [13].

From the literature [12 - 17] it is known that there are intervarietal and intravarietal variability of cereals in their ability to stimulate associative fixation of molecular nitrogen.

Our studies of potential nitrogenase activity in rhizosplan of winter wheat plants in field experiments have shown that the range of studied index is characterized by significant fluctuations during not only plants growing season but also through the same phenological stage in different research years $[18,19]$.

The results obtained indicate that nitrogen fixation is a mobile process, influenced by numerous environmental factors (temperature, humidity, stage of plant development, number of root exosmosis products etc.). The high variability of atmospheric nitrogen fixation is also caused by the dynamic processes of nitrogen transformation in the soil (denitrification, ammonification, nitrification) and subsequent conversion of received nitrogen compounds [18].

Significant influence of environmental factors on nitrogenase activity prevents evaluation of cereals varieties by their nitrogen fixation potential in field experiments. Moreover, field determination of associative nitrogen fixation is laborious method prolonged process, which make simultaneous analysis of a large number of plants impossible.

Productive tilling capacity, number of grains in ear, grain size and resistance to pathogens are traditionally considered in breeding of cereal plants. However, there is a significant variability based on the nitrogen fixation potential with no selection performed in this direction, which determines the importance of search for varieties with high nitrogen fixation potential in root zone.

Nowadays there are only few studies interactions between plants and plantbreeding grounds increased ability to stimulate associative nitrogen fixation. The presence of positive genetic correlations between individual plant-breeding signs 
and increased ability for associative nitrogen fixation was established. At the same time there are reports indicating that only about $30 \%$ of plants and cereal families can inherit an increased ability to prompt associative nitrogen fixation [20].

The study of genetic traits of plants that contribute to the formation of highly active plant-microbial associations in regards of nitrogen fixation may help to develop new approaches to solving the urgent problem - improvement of plant nutrition by means of biological nitrogen. Available publications on the plant genome control over the associative nitrogen fixation process require analysis, extra experimental data and estimation of the current state of plant genetics basing on the plants' capacity for activation of associative nitrogen fixation.

This study was aimed to estimate nitrogen fixation potential of winter wheat varieties and look for varieties with the increased ability to stimulate associative nitrogen fixation in controlled greenhouse experiment.

Materials and methods. Five modern promising varieties of soft winter wheat were studied: Albatros Odeskiy, Odeska 267, Kiriya, Zolotokolosa, Lybid.

The greenhouse experiment was conducted on leached shallow light loam chernozem on loess-like loams. Vessels $(200 \mathrm{ml})$ were filled with pre-sifted and freed from plant residues soil. 3-4 seeds of winter wheat of each variety were seeded per each vessel. On the $3-5$ day after emergence the single seedling was left in each vessel and was grown for three weeks in luminostat conditions (light intensity $-2000-2500$ lux, photoperiod -16 hours, temperature $26 \pm 2{ }^{\circ} \mathrm{C}$ ). Soil moisture was maintained on $60 \%$ level of the total moisture capacity. Experiments repetition - five-fold. In total 45 - 55 plants of each variety were examined.

Ppotential nitrogenase activity of plant roots was determined using acetyleneethylene method $[4,5]$. For this, roots were gently removed from the soil, washed out under the tap water, chopped and placed in a sterile vials (40 cubic $\mathrm{cm}$ ) with cotton-gauze plugs with $5 \mathrm{ml}$ of semisolid medium Dobereyner added [5]. In three days vials were sealed, followed by acetylene injection ( $10 \%$ by volume of the gas phase in the vial) and overnight incubation at temperature $26-28{ }^{\circ} \mathrm{C}$. Samples were analyzed on a gas chromatograph "Chrom-4" with flame ionization detector. Column length $370 \mathrm{~cm}$, filled with chromosorb $\beta$ - $\beta$ '-oxydipropionitrile. Thermostat temperature $-50{ }^{\circ} \mathrm{C}$, carrier gas - nitrogen, gas flow (in $\mathrm{ml} /$ minute): hydrogen -30 nitrogen -100 , air -500 .

Results and discussion. The results of the potential nitrogenase activity in the root zone of plants of different varieties of winter wheat have shown the significant fluctuations of this index (Table 1). Thus, studied wheat varieties have differed in 5.6 - 13.7 times by potential activity nitrogenase sign, indicating the existence of intervarietal variability of winter wheat plants.

Determination of the potential nitrogen fixation activity on the roots of sufficient number of plants of each variety ( $45-55$ plants) allows estimation of intervarietal variability of winter wheat plants by their nitrogen fixation potential. The results obtained for Albatros Odeskiy, Kiriya and Zolotokolosa are depicted in Figure 1, for Lybid and Odeska 267 - on Figure 2. 
TABLE 1. Potential nitrogen fixation activity in roots of winter wheat (greenhouse experiment)

\begin{tabular}{|c|c|}
\hline Varieties & $\begin{array}{c}\text { Potential nitrogen fixation activity (mean } \\
\text { values), nmol of ethylene / plant / hour }\end{array}$ \\
\hline Albatros Odeskiy & $3,05 \pm 0,19$ \\
\hline Odeska 267 & $17,02 \pm 1,41$ \\
\hline Kiriya & $27,92 \pm 1,42$ \\
\hline Lybid & $31,31 \pm 3,40$ \\
\hline Zolotokolosa & $41,86 \pm 1,14$ \\
\hline
\end{tabular}

Thus, Albatros Odeskiy (Fig. 1) is characterized by low nitrogen fixation potential with a fluctuations range of potential nitrogenase activity from 0 to $7 \mathrm{nmol}$ ethylene / plant / hour. This variety is equally rich in plants with low and high values of associative nitrogen fixation normally distributed among the plants.

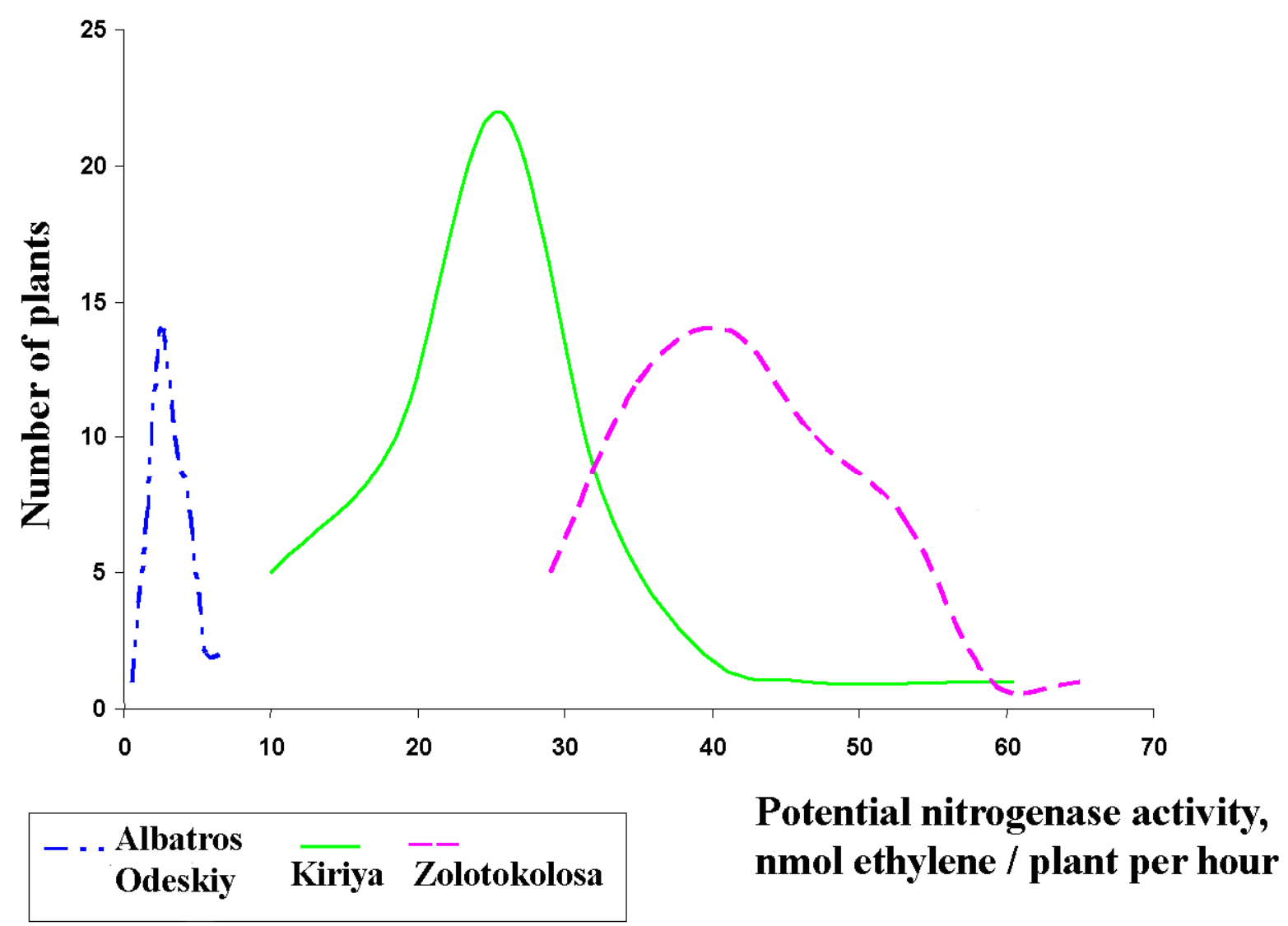

FIGURE. 1. Intervarietal variability of Albatros Odeskiy, Kiriya and Zolotokolosa varieties by their ability to stimulate associative nitrogen fixation. 
Nitrogen fixation activity in the root zone of plants of Kiriya variety differs from 5 to $71 \mathrm{nmol}$ of ethylene / plant / hour, with the maximum values of the sample (almost 49\%) being in the range of $22-29 \mathrm{nmol}$ of ethylene / plant / hour. Number of plants with low and high nitrogen fixation activity is approximately the same and is respectively 22.2 and $28.9 \%$ (Fig. 1). Kiriya variety has sufficiently high nitrogen fixation potential as compared with Albatros Odeskiy.

The variability range of Zolotokolosa variety was slightly narrower than the one of Kiriya, and was $26-68 \mathrm{nmol}$ of ethylene / plant / hour. It almost evenly rich in plants with minimum, maximum and average values of nitrogen fixation activity in the root zone. Thus, the average value of the sample (31\%) were in the range $38-$ 44 nmol of ethylene / plant / hour (Fig. 1).

Varieties Lybid and Odeska 267 (Fig. 2) were characterized by an asymmetric distribution of potential nitrogenase activity values, predominating by plants with lower nitrogen fixation potential. Nevertheless, the populations of these varieties have plant genotypes with high nitrogen fixation potential. In this regard, there is the possibility of further varieties improvement by this sign.

Among the studied varieties Zolotokolosa is drawing ones attention by its genetic homogeneity and high nitrogen fixation potential. This variety can be recommended for use in breeding work as the source of increased ability to stimulate associative nitrogen fixation.

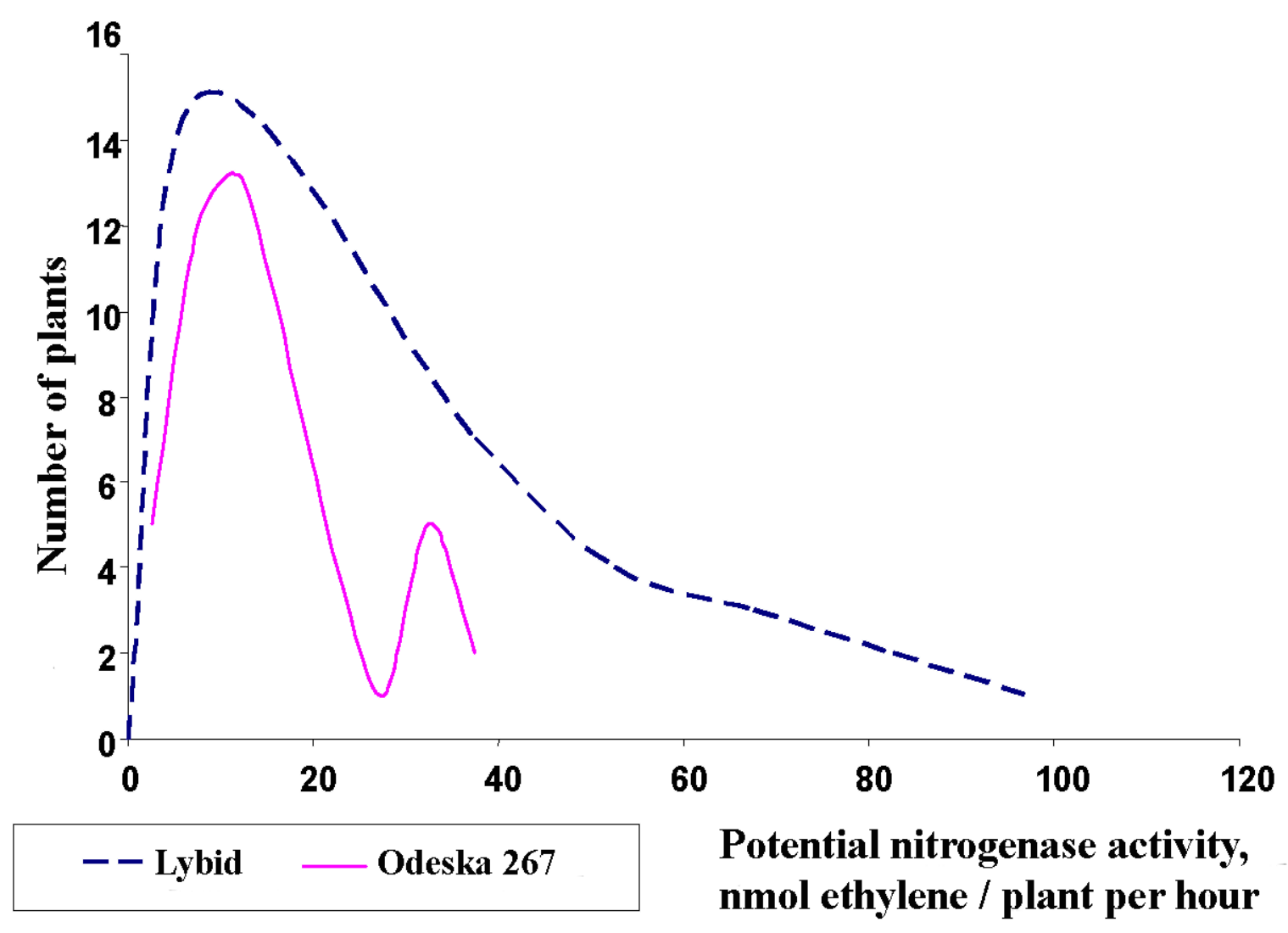

FIGURE 2. Intravarietal variability of Lybid and Odeska 267 varieties by their associative nitrogen fixation ability. 
Thus, assessment of intervarietal and intravarietal variability of winter wheat plants by their nitrogen fixation potential have shown advantages of controlled experimental methods. At this, the number of investigated plants of each variety should be sufficient in order to obtain normal distribution of values of potential nitrogenase activity in the root zone of plants (average of 50 plants). Abundance of plant genotypes with high nitrogen fixation activity in roots among the varieties stipulate high nitrogen fixation potential of variety.

The results obtained can be used by plant breeders for development of new and improvement of existing varieties of winter wheat plants. Production of crops capable of complete development not only through the use of fertilizers, but also by interacting with associative nitrogen fixation microorganisms will partially replace mineral nitrogen with biological one. Advantages of biological nitrogen if compared to nitrogen fertilizers are well known - it causes no pollution and disturbance of ecological systems. In addition, the replacement of mineral nitrogen with biological saves costs and energy resources. According to the literature, introduction of varieties with high nitrogen fixation potential can result in replacement of up to 60 $\mathrm{kg} /$ ha of mineral nitrogen with biological nitrogen $[6,7,13,17]$. Besides, it is necessary to pay attention to the inheritance patterns of the increased capacity for associative nitrogen fixation, since this problem is little-investigated, and there are only few data on this issue [20]. Breeding of varieties with high nitrogen fixation potential will guarantee high yield quality without the excessive use of mineral nitrogen fertilizers and preservation of agricultural landscapes in good condition. 